\title{
Olefins from Biobased Sugar Alcohols via Selective, Ru-mediated reaction in Catalytic Phosphonium Ionic Liquids
}

\author{
Maxime Stalpaert ${ }^{\dagger, \S}$, Kwinten Janssens ${ }^{\dagger, \S}$, Carlos Marquez $^{\dagger}$, Mickaël Henrion $^{\dagger}$, Aram L. \\ Bugaev $^{\ddagger}$, Alexander V. Soldatov ${ }^{\ddagger} \&$ Dirk De Vos ${ }^{\dagger *}$ \\ † Centre for Membrane separations, Adsorption, Catalysis and Spectroscopy for Sustainable Solutions \\ (cMACS), Department of Microbial and Molecular Systems (M2S); KU Leuven, Celestijnenlaan 20oF, post \\ box 2454, 3001 Leuven (Belgium). \\ ‡ The Smart Materials Research Center, Southern Federal University, Sladkova 178/24, 34409o Rostov-on- \\ Don, Russia
}

\begin{abstract}
Hydrodeoxygenation (HDO) of sugar alcohols could be a valuable reaction for the renewable production of alkenes. However, reports on deoxygenation of longer polyols (e.g. erythritol, xylitol, sorbitol) to mono-alkenes are scarce, especially when using $\mathrm{H}_{2}$ as reducing agent. Here we design a conceptually different catalyst system for polyol conversion to olefins, containing a selective Ru hydrogenation function (e.g. $\mathrm{RuBr}_{3}$ ) in an ionic liquid that dehydrates alcohols (tetrabutylphosphonium bromide, $\mathrm{Bu}_{4} \mathrm{PBr}$ ). This system performs $\mathrm{HDO}$ of erythritol to butenes in yields up to $69 \%$. Strikingly, overreduction to less valuable butane is effectively suppressed. We show that in situ formed CO is crucial in the formation and stabilization of the active and selective catalyst. The actual hydrogenation catalyst is identified as a Ru carbonyl bromide species, as demonstrated by FTIR and XANES. Finally, we show that this HDO also works for more economically relevant polyols: glycerol, xylitol and sorbitol, leading to propene, pentenes and hexenes as main products respectively. KEYWORDS: homogeneous catalysis, hydrodeoxygenation, biomass, Ruthenium, ionic liquids, $\mathrm{CO}$
\end{abstract}

\section{Introduction:}

Sugar alcohols are abundantly accessible bio-based compounds and, as a result, they are very promising as renewable resources. ${ }^{1-3}$ Glycerol is an important (> $10 \mathrm{wt} \%$ ) side product from biodiesel production, ${ }^{4,5}$ while erythritol can be formed fermentatively from glucose, xylose or glycerol..$^{6-8}$ Xylitol and sorbitol are produced by hydrogenation of xylose and glucose respectively using Ni or Ru catalysts. ${ }^{1-3}$ Furthermore, also the direct production of these sugar alcohols from (hemi)cellulose is viable., ${ }^{9,10}$ While sugar alcohols themselves have applications, e.g. as sweeteners, ${ }^{1}$ selective deoxygenation greatly expands their potential. Different deoxygenation methods have been reported, mainly to alkanes ${ }^{11-13}$ and shorter chain polyols or alcohols ${ }^{14}$. Some transformations to olefins (of the same chain length) have also been reported, especially for the production of propene from glycerol. ${ }^{15-24}$ Transformations of higher polyols to unsaturated hydrocarbons on the other hand are much more rare. One interesting tool for such deoxygenations is the deoxydehydration (DODH) reaction, typically catalyzed by $\mathrm{Re}$, Mo or V, which removes OHgroups pairwise from vicinal diols in a reverse cycloaddition. Transformation of erythritol to butadiene over Re- or Mo-based DODH catalysts has been performed with reducing agents such as hydroaromatics, ${ }^{25}$ alcohols, ${ }^{26-28}$ triphenylphosphine, ${ }^{27,29,30}$ or $\mathrm{Na}_{2} \mathrm{SO}_{3}{ }^{31} \mathrm{Use}^{1}$ of $\mathrm{H}_{2}$ is possible with a sophisticated $\mathrm{ReOx}-\mathrm{Au} / \mathrm{CeO}_{2}$ catalyst; the DODH of erythritol with this system forms mainly butadiene, while butenes are formed as a minor side product (3\%). ${ }^{32}$ In addition, also DODH of xylitol to 1,3-pentadiene ${ }^{33}$ and of sorbitol to 1,3,5-hexatriene ${ }^{26}$ have been reported, using formic acid and 3-pentanol as reducing agent, respectively. Only one non-DODH deoxygenation of higher sugar alcohols to olefins has been reported: a transformation of sorbitol to hexenes using silanes $\left(\mathrm{R}_{3} \mathrm{SiH}\right.$ or $\left.\mathrm{R}_{2} \mathrm{SiH}_{2}\right)$ as reducing agents, entailing significant cost and waste co-production. ${ }^{34}$ Summarizing, the number of reports on deoxygenation of polyols to mono-olefins is limited, especially if $\mathrm{H}_{2}$ is to be used, which is the preferred industrial 
reducing agent. Nevertheless, such a process would be very valuable, since biosourced higher olefins are in high demand as non-fossil drop-in building blocks.

Conversion of a polyol to an olefin implies a combination of dehydration and reduction reactions. Dehydration of a vicinal diol motive leads, via enol-to-keto tautomerism, to carbonyl compounds (Figure $1 \mathrm{~b}$ ). We hypothesized that if a fast dehydration were combined with exclusive hydrogenation of $\mathrm{C}=\mathrm{O}$ bonds, even in the presence of $\mathrm{C}=\mathrm{C}$ bonds, the overall sequence may result in the stepwise deoxygenation to an olefin, as a kinetically stable end product. In designing a catalytic system, we first selected tetraalkylphosphonium halogenides as performant dehydration media. We previously showed that in particular tetrabutylphosphonium bromide $\left(\mathrm{Bu}_{4} \mathrm{PBr}\right)$, together with an acid cocatalyst, forms a stable and recyclable catalytic system for dehydrations, ${ }^{35-36}$ e.g. of 1,4-butanediol to 1,3-butadiene. These reactions proceed via $\mathrm{H}^{+}$-assisted nucleophilic substitution of $-\mathrm{OH}$ by $\mathrm{Br}^{-}$, followed by $\mathrm{HBr}$ elimination and $\mathrm{C}=\mathrm{C}$ formation (Figure $1 \mathrm{a}$ ). To allow for full deoxygenation of compounds with more than one hydroxy group per two carbons, as in the desired sugar alcohol to olefin route, $\mathrm{Bu}_{4} \mathrm{PBr}$ needs to be combined with a hydrogenation catalyst with very high $\mathrm{C}=\mathrm{O}$ over $\mathrm{C}=\mathrm{C}$ selectivity. Such a hydrodeoxygenation (HDO) would be formally similar to, but mechanistically completely different from the classical DODH reaction, and would be a conceptually new complement to DODH.

a) Previous work: dehydration in tetrabutylphosphonium bromide $\left(\mathrm{Bu}_{4} \mathrm{PBr}\right)$

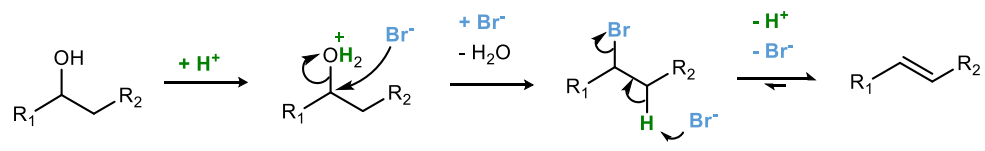

b) Aim of this report: combine $\mathrm{Bu}_{4} \mathrm{PBr}$ catalysis with metal catalyzed carbonyl hydrogenation

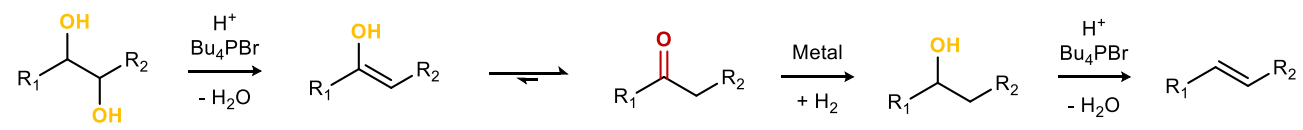

Figure 1. Summary of previous work and aim of this report.

\section{Results and discussion}

\section{Identification of a catalyst for selective olefin production}

Erythritol was chosen as a model sugar alcohol, as we expected it to lead to a moderately complex product distribution relative to sugar alcohols of shorter and longer chain length. Reactions were performed in conditions that were previously demonstrated conducive for dehydration $\left(200^{\circ} \mathrm{C}, 3.4\right.$ eq. $\left.\mathrm{Bu}_{4} \mathrm{PBr}, 5 \mathrm{~mol} \% \mathrm{HBr}, 4 \mathrm{~h}\right), 35.36$ in the presence of $2 \mathrm{~mol} \%$ metal catalyst, $40 \mathrm{obar} \mathrm{H}_{2}$ and a dodecane phase for product extraction. Full conversion of erythritol is reached in these conditions, like in most reactions of this paper. In the absence of a metal catalyst the main product is 2,3-butanedione, formed via two successive dehydrations (Figure 2). In line with established insights in the $\mathrm{Bu}_{4} \mathrm{PBr}-\mathrm{HBr}$ system, ${ }^{35}$ this confirms that the dehydration typically starts by nucleophilic substitution with $\mathrm{Br}^{-}$at the sterically more accessible terminal $-\mathrm{CH}_{2} \mathrm{OH}$ group, followed by $\mathrm{HBr}$ loss and ketone formation at $\mathrm{C}_{2}$.

To further convert these carbonyl compounds, we focused on homogeneous Ru hydrogenation catalysts, since some examples of selective, Ru-catalyzed hydrogenations of $\mathrm{C}=\mathrm{O}$ groups to alcohols are known, for example from Noyori's seminal work; note however that these reactions proceed in vastly different conditions. ${ }^{37-39}$ Addition of several $\mathrm{Ru}(\mathrm{II})$ and $\mathrm{Ru}(\mathrm{III})$ complexes leads to good butene yields (1-butene, cis- and trans-2-butene), while $\mathrm{Ru}_{3}(\mathrm{CO})_{12}$, with $\mathrm{Ru}$ in the zerovalent state, performs poorly. Note that, in contrast to the DODH reaction, butenes rather than the expected butadiene are formed, resulting in the first high-yielding HDO of erythritol to butenes. The simple Ru salts $\mathrm{RuCl}_{3}$ and $\mathrm{RuBr}_{3}$ lead to surprisingly high butene yield and selectivity. Complexes with electronrich ligands, like $\mathrm{RuCl}_{2}\left(\mathrm{PPh}_{3}\right)_{3}$ and $\mathrm{Ru}(\mathrm{acac})_{3}$ lead to increased overreduction to butane (acac $=2,4$-pentanedionate). By contrast, $\left[\mathrm{RuCl}_{2}(\mathrm{CO})_{3}\right]_{2}$ and $\left[\mathrm{RuBr}_{2}(\mathrm{CO})_{3}\right]_{2}$, the latter synthesized following a literature procedure, ${ }^{40}$ lead to 57 and $67 \%$ yields of butenes respectively, without any overreduction to butane, suggesting a positive effect of the electron withdrawing ligand CO. In these high-yielding reactions, a good mass balance is achieved, because aldol condensation of carbonyl intermediates is largely suppressed by faster hydrogenation (Figure $\mathrm{S} 1$ ). A reaction without substrate for $48 \mathrm{~h}$ confirmed that the butenes indeed originate from erythritol, rather than from breakdown of the tetrabutylphosphonium cation. Furthermore, $\mathrm{H}_{2}$ is needed as reducing agent, as butenes or butanone are not 
formed in its absence (Figure 2), ruling out transfer hydrogenation of alcohol substrates or intermediates as main reduction mechanism. Finally, other homogeneous or heterogeneous noble metal catalysts were tested, e.g. based on Pt or Pd; most lead to butanone as the main product, and butene yields are very low or null (Figure S2).

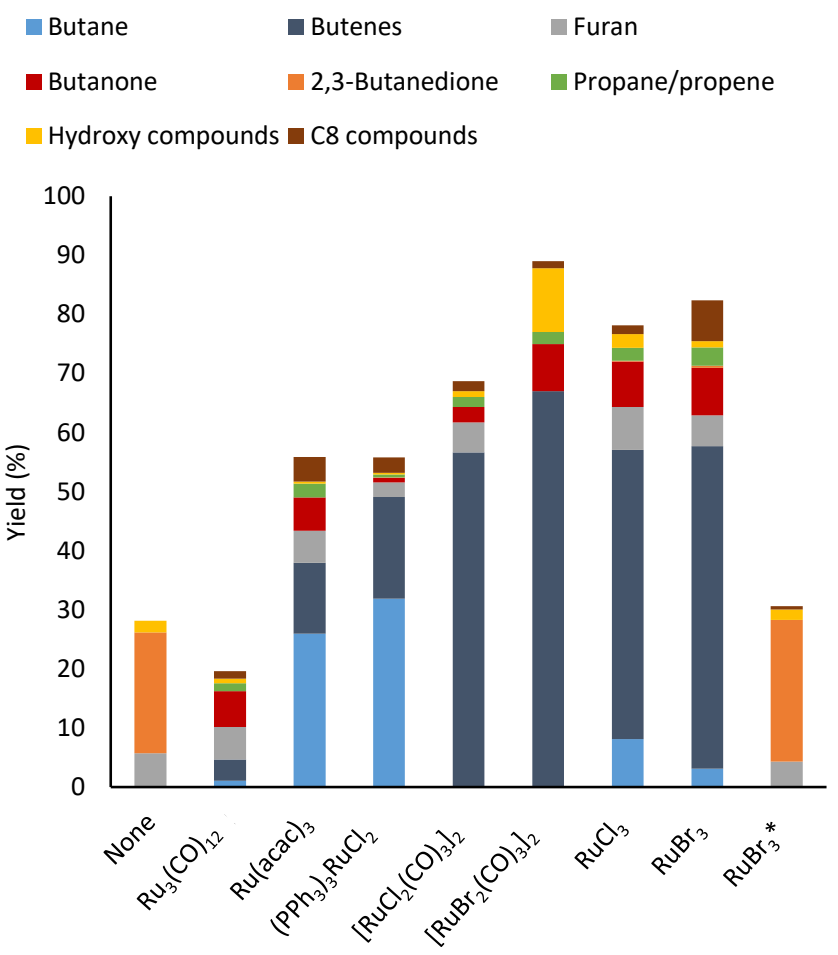

Figure 2. Identification of best metal catalyst for hydrodeoxygenation of erythritol in tetrabutylphosphonium bromide. Conditions: $0.5 \mathrm{mmol}$ erythritol, $1.7 \mathrm{mmol} \mathrm{Bu}_{4} \mathrm{PBr}$, $0.01 \mathrm{mmol} \mathrm{Ru}(2 \mathrm{~mol} \%)$, $0.025 \mathrm{mmol} \mathrm{HBr}, 1 \mathrm{~mL}$ dodecane, $200{ }^{\circ} \mathrm{C}, 40$ bar $\mathrm{H}_{2}, 4$ h. Hydroxy compounds = 1,4-anhydroerythritol and 3,4-hydroxybutanone; acac = acetylacetonate; $\mathrm{PPh}_{3}=$ triphenylphosphine. * 40 bar $\mathrm{N}_{2}$.

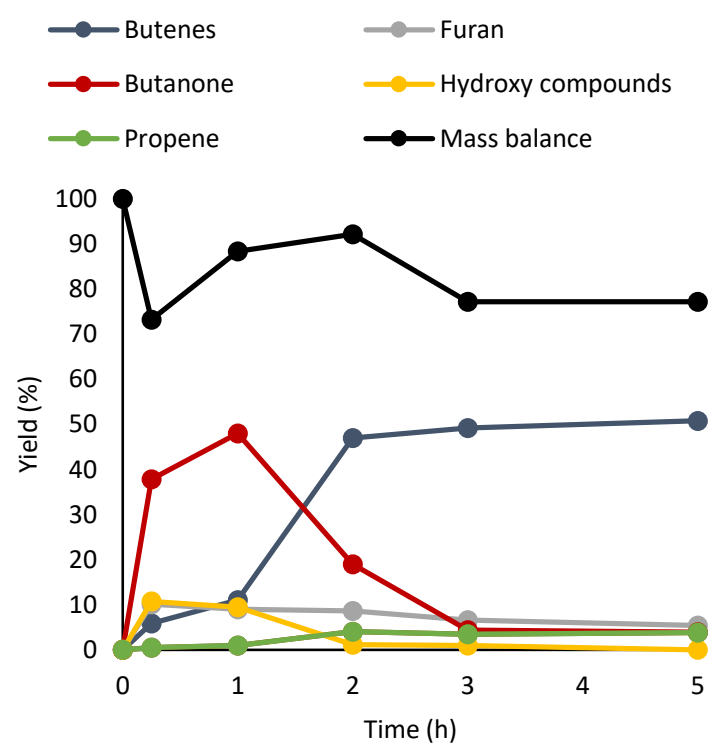


Figure 3. Time profile of erythritol reaction with $\mathrm{RuBr}_{3}$ as a catalyst. Conditions: $0.5 \mathrm{mmol}$ erythritol, $1.7 \mathrm{mmol} \mathrm{Bu}{ }_{4} \mathrm{PBr}$, $0.005 \mathrm{mmol} \mathrm{RuBr}_{3}\left(1 \mathrm{~mol} \%\right.$ ), $0.0125 \mathrm{mmol} \mathrm{HBr}, 1 \mathrm{ml}$ dodecane, $210^{\circ} \mathrm{C}$, 40 bar $\mathrm{H}_{2}$.

The reaction with $\mathrm{RuBr}_{3}$, as a simple and effective $\mathrm{Ru}$ precursor, was subjected to a brief parametric optimization (temperature, pressure, type and amount of IL and acid) at a lower catalyst loading of 1 mol\% (Figure $\mathrm{S}_{4}-8$ and Table $\mathrm{S} 1$ ). In the conditions identified ( $3.4 \mathrm{eq} . \mathrm{Bu}_{4} \mathrm{PBr}, 1 \mathrm{~mol} \% \mathrm{RuBr}_{3}, 2.5 \mathrm{~mol} \% \mathrm{HBr}, 210{ }^{\circ} \mathrm{C}$ and 40 bar $\mathrm{H}_{2}$ ), the formation of products over time was followed (Figure 3). The initial turnover frequency (TOF) of the Ru catalyst for hydrogenation/reduction is quite high, at $376 \mathrm{~h}^{-1}$ (counting two and three hydrogenations/reductions respectively per molecule of butanone and butene formed). At first, butanone accumulates, reaching a $48 \%$ yield after $1 \mathrm{~h}$, but it is gradually converted to butenes, leading to a $51 \%$ yield after $5 \mathrm{~h}$. This accumulation implies that dicarbonyls, such as butanedione, and hydroxycarbonyl compounds are hydrogenated quickly, while the hydrogenation of butanone is a kinetically slow step. Possibly, a second functional group, like in butanedione, is required to bring the $\mathrm{C}=\mathrm{O}$ group close to the Ru centre; a similar substrate directed hydrogenation has been described in other ketone hydrogenations catalyzed by homogeneous $\mathrm{Ru} .{ }^{41}$

\section{Role of CO}

With the hydrogenation of butanone having been identified as the slow step, this reaction was studied separately, with either $\left[\mathrm{RuBr}_{2}(\mathrm{CO})_{3}\right]_{2}$ or $\mathrm{RuBr}_{3}$, in otherwise identical conditions (3.4 eq. $\mathrm{Bu}_{4} \mathrm{PBr}, 1 \mathrm{~mol} \% \mathrm{Ru}, 5 \mathrm{~mol} \% \mathrm{HBr}, 210$ ${ }^{\circ} \mathrm{C}$, 40 bar $\mathrm{H}_{2}$ ). Using $\left[\mathrm{RuBr}_{2}(\mathrm{CO})_{3}\right]_{2}$, butanone is efficiently transformed to butenes with $>90 \%$ selectivity, but with $\mathrm{RuBr}_{3}$, hardly any butenes are formed (Table 1, entries 1,2). The hydrogenation activity nevertheless can be restored with 0.125 bar of CO in the atmosphere, corresponding to an 20:1 CO to Ru ratio (Table 1, entry 3). Higher CO partial pressures clearly slow down the reduction of butanone to butenes (Table 1, entries 4,5). This evidences that excessive coordination of Ru by $\mathrm{CO}$ must be avoided in order to obtain the most active hydrogenation catalyst. Since dosing low partial pressures of $\mathrm{CO}$ is non-trivial when $\mathrm{H}_{2}$ is simultaneously present at high pressure (4o bar), it was decided to add small amounts of formaldehyde ( $20 \mathrm{~mol} \%$; $20: 1 \mathrm{HCHO}$ to $\mathrm{Ru}$ ratio) as an alternative source of $\mathrm{CO}$. Formaldehyde can indeed be dehydrogenated in situ to form CO.42 As expected, $\mathrm{HCHO}$, in combination with $\mathrm{RuBr}_{3}$ generates an active catalyst for butanone to conversion to butenes, while the corresponding alcohol, methanol, is incapable to do so (Table 1, entries 6,7). Generally, aldehydes are easily decarbonylated, and any aldehyde therefore is a potential in situ source of CO. Thus, the aldehyde 3-oxobutanal, when used as an additive in the RuBr $\mathbf{r}_{3}$ catalyzed reduction of butanone, facilitates butanone reduction to butenes, while 2,3-butanedione does not (Table 1 , entries 8-9). When the reaction is started from 2,3-butanedione as the substrate (Table 1, entry 10), in the absence of added $\mathrm{CO}, \mathrm{RuBr}_{3}$ again fails to form selectively butenes. Although full conversion was reached, poor chemoselectivity to butenes was observed in combination with a poor mass balance resulting from significant aldol condensation. This proves that also for the easier reduction of 2,3-butanedione, a $\mathrm{Ru}$ carbonyl compound, rather than simple $\mathrm{RuBr}_{3}$ is the desired catalyst. Since 3-oxobutanal is a minor product of the acid-catalyzed double dehydration of erythritol, it becomes clear that the reaction starting from erythritol could produce autogenous CO. This explains why acceptable hydrogenation activity and butene yields were found even with simple $\operatorname{RuBr}_{3}$, in the absence of any added $\mathrm{CO}$ or HCHO (Figures 2 and 3 ).

Table 1. Influence of $\mathrm{CO}$, formaldehyde and other additives on reduction of the butanone intermediate.

\begin{tabular}{|c|c|c|c|c|c|c|}
\hline \multirow{2}{*}{ Entry } & \multirow{2}{*}{ Catalyst } & \multirow{2}{*}{ Additive } & \multicolumn{3}{|c|}{ mol percentage $(\%)$} & \multirow{2}{*}{$\begin{array}{l}\text { Conversion } \\
(\%)\end{array}$} \\
\hline & & & Butane & Butenes & Butanone & \\
\hline 1 & {$\left[\mathrm{RuBr}_{2}(\mathrm{CO})_{3}\right]_{2}$} & None & $\mathrm{o}$ & 76 & 16 & 84 \\
\hline 2 & $\mathrm{RuBr}_{3}$ & None & 1 & 1 & 56 & 44 \\
\hline 3 & $\mathrm{RuBr}_{3}$ & 0.125 bar $\mathrm{CO}$ & $\mathrm{o}$ & 50 & 44 & 56 \\
\hline 4 & $\mathrm{RuBr}_{3}$ & 0.5 bar CO & $\mathrm{o}$ & 29 & 63 & 37 \\
\hline 5 & $\mathrm{RuBr}_{3}$ & 1 bar $\mathrm{CO}$ & $\mathrm{o}$ & 26 & 64 & 36 \\
\hline 6 & $\mathrm{RuBr}_{3}$ & Formaldehyde & 3 & 72 & 13 & 87 \\
\hline 7 & $\mathrm{RuBr}_{3}$ & Methanol & 1 & 2 & 66 & 34 \\
\hline 8 & $\mathrm{RuBr}_{3}$ & 3-Oxobutanala,b & 2 & 57 & 30 & 70 \\
\hline 9 & $\mathrm{RuBr}_{3}$ & Butanedione & 3 & 4 & 70 & 30 \\
\hline $10^{\mathrm{c}}$ & $\mathrm{RuBr}_{3}$ & None & 7 & 14 & 13 & 99 \\
\hline
\end{tabular}


Conditions: $0.5 \mathrm{mmol}$ butanone, $1.7 \mathrm{mmol} \mathrm{Bu} 4 \mathrm{PBr}$, $0.005 \mathrm{mmol} \mathrm{Ru}(1 \mathrm{~mol} \%)$, $0.025 \mathrm{mmol} \mathrm{HBr}$, o.1 mmol additive, $1 \mathrm{~mL}$ dodecane, 40 bar $\mathrm{H}_{2}, 2 \mathrm{~h}, 210^{\circ} \mathrm{C}$. a Since these additives also form products such as butenes and butanone in these conditions, the expected yield of these products from $0.1 \mathrm{mmol}$ additive is subtracted; ${ }^{\mathrm{b}}$ Aldehyde in dimethyl acetal form; c reaction with $0.5 \mathrm{mmol} 2,3$-butanedione.

Besides promoting the Ru-catalyzed hydrogenation of ketone intermediates, the presence of $\mathrm{CO}$ also appears to suppress the overreduction of butenes to butane. This is illustrated by data for the $\mathrm{RuBr}_{3}$-catalyzed conversion of erythritol (Table 2). Addition of $\mathrm{HCHO}$ (as a CO precursor) to reactions with 2 or $5 \mathrm{~mol} \% \mathrm{RuBr}_{3}$ fully suppresses overreduction of butenes to butane (Table 2, entries 4 vs. 3, and 6 vs. 5). With $5 \mathrm{~mol} \% \mathrm{Ru}$, the butene yield even increases to $66-69 \%$ (Table 2 , entries 6,7 ). Strikingly, a clear visual difference is observed between reactions with overreduction and those without; a grey IL is formed in the former case, suggesting metallic Ru, while in the latter case a yellow IL is obtained (Figure S1). FTIR analysis of the reactor headspace confirmed formation of CO, part of which most likely ligates to the Ru catalyst, thus stabilizing it towards reduction and aggregation as zerovalent metal. Importantly, FTIR analysis also detected CO in the reactions without added formaldehyde. This confirms that $\mathrm{CO}$ is also formed from a reaction intermediate, most likely an aldehyde like 3-oxobutanal, as Ru catalysts are well-known for decarbonylation of aldehydes. ${ }^{43-45}$ The formation of propene as a side product (Figure 2) is consistent with in situ decarbonylation of 3-oxobutanal to form acetone, followed by HDO of acetone by ketone reduction and dehydration.

Table 2. Influence of formaldehyde on the $\mathrm{RuBr}_{3}$-catalyzed $\mathrm{HDO}$ of erythritol.

\begin{tabular}{|l|l|l|l|l:l|}
\hline \multirow{2}{*}{ Entry } & \multirow{2}{*}{ mol\% Ru } & \multirow{2}{*}{ HCHO } & \multicolumn{2}{|l|}{ Yield (\%) } & \\
\cline { 4 - 6 } & & & Butane & Butenes & Butanone \\
\hline 1 & 1 & - & 0 & 43 & 18 \\
\hline 2 & 1 & + & 0 & 27 & 25 \\
\hline 3 & 2 & - & 3 & 46 & 17 \\
\hline 4 & 2 & + & 0 & 55 & 14 \\
\hline 5 & 5 & - & 4 & 52 & 13 \\
\hline 6 & 5 & + & 0 & 66 & 1 \\
\hline 7 & $5 *$ & + & 0 & 69 & 1 \\
\hline
\end{tabular}

Conditions: $0.5 \mathrm{mmol}$ erythritol, $1.7 \mathrm{mmol} \mathrm{Bu} 4 \mathrm{PBr}, 0.025 \mathrm{mmol} \mathrm{HBr}, 1 \mathrm{~mL}$ dodecane, $40 \mathrm{bar} \mathrm{H} 2,2 \mathrm{~h}, 210^{\circ} \mathrm{C}$. When $\mathrm{HCHO}$ was added, it was added at a constant $\mathrm{HCHO}: \mathrm{Ru}$ ratio of $16 .{ }^{*}$ reaction with $0.05 \mathrm{mmol} \mathrm{HBr}$. 


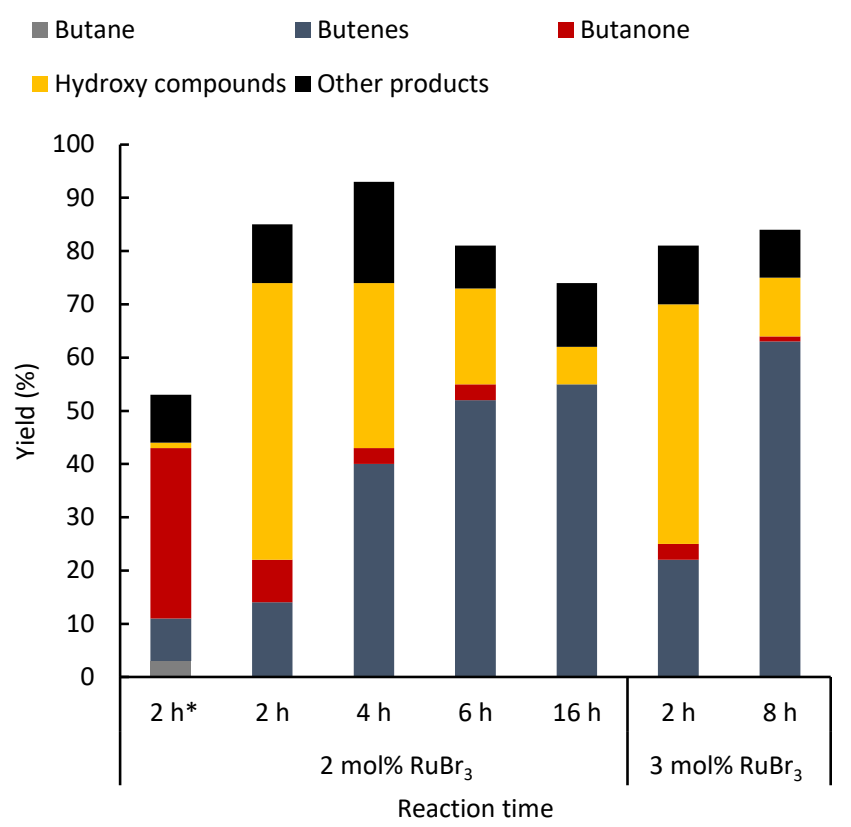

Figure 4. $\mathrm{HDO}$ of erythritol at $180^{\circ} \mathrm{C}$, after catalyst pretreatment with formaldehyde at $210^{\circ} \mathrm{C}$. General conditions: 0.5 mmol erythritol, $1.7 \mathrm{mmol} \mathrm{Bu}_{4} \mathrm{PBr}, 0.025 \mathrm{mmol} \mathrm{HBr}, 1 \mathrm{~mL}$ dodecane, 40 bar $\mathrm{H}_{2} .{ }^{*}=$ reaction without pretreatment.

The previous reactions demonstrated that a limited amount of $\mathrm{CO}$ is needed to create the active hydrogenation catalyst, to prevent reduction of the catalyst to metal, and thus to decrease the overreduction to butane. However, if too much $\mathrm{CO}$ is present, either formed autogenously from erythritol, or from added $\mathrm{HCHO}$, it has a negative impact on the reaction, especially at low $\mathrm{RuBr}_{3}$ contents. This is clear from the $\mathrm{HDO}$ of erythritol with $1 \mathrm{~mol} \% \mathrm{RuBr}_{3}$, with or without added HCHO (Table 2, entries 1 and 2). Therefore, it would be advantageous to perform the hydrodeoxygenation at an optimal, constant concentration of $\mathrm{CO}$, without generating too much $\mathrm{CO}$ by decarbonylation of 3-oxobutanal. The latter is enabled by performing reactions at $180^{\circ} \mathrm{C}$, where decarbonylation is very slow, as evidenced by a negligible yield of propene (Figure $\mathrm{S}_{5}$ ). In an even more advantageous procedure, a catalyst pretreatment step is performed, in which the $\mathrm{RuBr}_{3}$ catalyst is activated at $210^{\circ} \mathrm{C}$ in $\mathrm{Bu}_{4} \mathrm{PBr}$ in the presence of formaldehyde but in the absence of erythritol; next reaction is started at $180^{\circ} \mathrm{C}$, with addition of erythritol. The yield of butenes clearly increased by including a catalyst pretreatment step, to $55 \%$ with $2 \mathrm{~mol} \% \mathrm{RuBr}_{3}$ and even to $65 \%$ with $3 \mathrm{~mol} \% \mathrm{RuBr}_{3}$, while still completely avoiding any overreduction to butane (Figure 4 ). Furthermore, the constant (minimal) concentration of $\mathrm{CO}$ in the reaction medium results in catalyst stability, as evidenced by successful catalyst recycling tests (Figure S14). The catalyst could be recycled up to 5 times before the butene yield decreased, presumably due to slower dehydration. The initial activity and selectivity of the system were regained after drying under vacuum.

\section{Catalyst characterization}

The catalytic results indicate that $\mathrm{CO}$, either formed from a reaction intermediate or added externally, plays an important role in the system. Most likely, CO binds to Ru and influences the catalyst as a ligand. We investigated this hypothesis by analyzing the Ru-containing IL after reaction starting from $1 \mathrm{~mol} \% \mathrm{RuBr}_{3}$ by FTIR spectroscopy. The IL solidifies quickly upon cooling (melting point around $100^{\circ} \mathrm{C}$ ) allowing to trap catalytically relevant species in the IL. The carbonyl stretching region of the FTIR spectrum (Figure 5) shows two medium-strength vibrations at 2112 and $2028 \mathrm{~cm}^{-1}$ and one weaker band at $1951 \mathrm{~cm}^{-1}$, characteristic of axial and radial CO vibrations in Ru-carbonyl compounds..$^{6}$ This is highly similar to the bands obtained for $\left[\operatorname{RuBr}_{2}(C O)_{3}\right]_{2}$ dissolved in $\mathrm{Bu}_{4} \mathrm{PBr}$, indicating the formation of a similar Ru species. In addition, also the Ru catalyst pretreated with $\mathrm{HCHO}$ in $\mathrm{Bu}_{4} \mathrm{PBr}$ correlates well 
with $\left[\mathrm{RuBr}_{2}(\mathrm{CO})_{3}\right]_{2}$. Hence, the catalyst pretreatment is a fast and facile step to circumvent the disadvantages of $\left[\mathrm{RuBr}_{2}(\mathrm{CO})_{3}\right]_{2}$ synthesis.
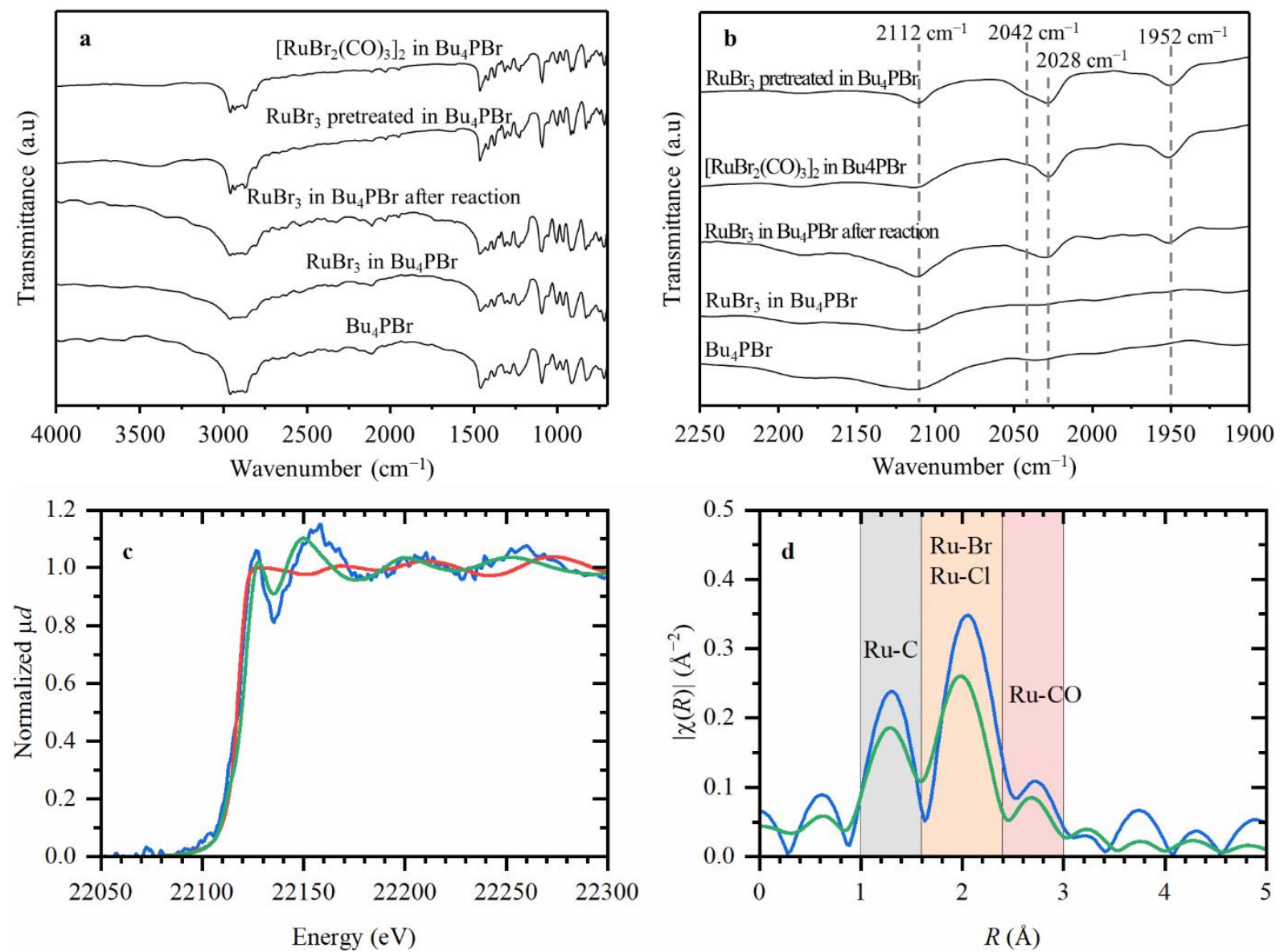

Figure 5. Characterization of $\mathrm{Ru}$ in tetrabutylphosphonium bromide ( $\mathrm{Bu}_{4} \mathrm{PBr}$ ). a) Fourier transform infrared (FTIR) spectrum; b) Zoom on carbonyl region of FTIR spectrum; c) X-ray absorption near edge structure (XANES) spectra of high concentration commercial $\mathrm{Ru}$ complexes: $\mathrm{RuBr}_{3}$ in $\mathrm{Bu}_{4} \mathrm{PBr}$ (red) and $\left[\mathrm{RuCl}_{2}(\mathrm{CO})_{3}\right]_{2}$ in $\mathrm{Bu}_{4} \mathrm{PBr}$ (green) and the low concentration Ru catalyst in $\mathrm{Bu}_{4} \mathrm{PBr}$ after reaction (blue); d) Fourier-transformed phase-uncorrected EXAFS spectra.

In addition, X-ray absorption near edge structure (XANES) and extended X-ray absorption fine structure (EXAFS) data were collected on a sample obtained in the same conditions for the catalyst and commercially available Ru complexes $\left(\left[\mathrm{RuCl}_{2}(\mathrm{CO})_{3}\right]_{2}\right.$ and $\mathrm{RuBr}_{3}$ dissolved in $\left.\mathrm{Bu}_{4} \mathrm{PBr}\right)$. XANES spectra (Figure ${ }_{5} \mathrm{c}$ ) evidence that the catalyst obtained after reaction is clearly distinct from the parent $\mathrm{RuBr}_{3}$, sharing similar spectral features with Ru halide carbonyl complexes. Furthermore, the FT-EXAFS of the catalyst is characterized by three peaks as in the Ru halide carbonyl complex (Figure 5d), which indicates a similar local surrounding of Ru ions in both samples. Due to low $\mathrm{Ru}$ concentration in the catalyst Figure $5 \mathrm{~d}$ shows only a qualitative comparison using $k^{1}$-weighted spectra in 1.7-9.0 $\AA^{-1}$ region. Quantitative fitting of the commercial sample in extended $k$-region confirms the expected $\mathrm{Ru}$ coordination (Figure S10-12). Summarizing, FTIR and EXAFS characterization demonstrate that the $\mathrm{RuBr}_{3} \mathrm{precursor}$ is transformed to a $\mathrm{Ru}(\mathrm{II})$ bromide carbonyl species in the reaction conditions.

\section{Study of putative intermediates and reaction network}

Next, we mapped the reaction network (Figure 6), by reacting a series of putative intermediates on the route from erythritol to butenes, with addition of formaldehyde for non-aldehyde substrates. Two products of double dehydration of erythritol, butanedione and 3-oxobutanal, the former being the main product in the absence of hydrogenation, lead to good yields of butenes, while the other $\mathrm{C}_{4}$ dicarbonyl, succinaldehyde, does not (Table 3 , entries 2-4). In addition, the enhanced $C_{3}$ yields from 3-oxobutanal confirm its susceptibility to decarbonylation. The hydrogenation products of butanedione and 3-oxobutanal are two hydroxyketones (4-hydroxybutanone, 3- 
hydroxybutanone; Table 3, entries 5-6), which in turn react smoothly to butenes in up to $65 \%$ yield. From these compounds, butanediols can be formed, which lead to even higher butene yields (> 85\%; entries 7-8). Alternatively, the hydroxyketones can be dehydrated to methyl vinyl ketone (MVK, entry 9), which leads to somewhat lower butene yields and mass balance, possibly because of polymerization. Next to butanone, 1-buten-3-ol and 2-buten-1ol (entries 11-12) are the most likely dehydration products of the diols. Remarkably, these allylic alcohols react selectively to butenes as well, without butane or butadiene formation. This implies that besides carbonyl hydrogenation, also hydrogenolysis of allylic alcohols or bromides is effected by the Ru catalyst. In particular allylic bromides are highly susceptible to hydrogenolysis (Figure S13). ${ }^{47}$ Finally, it should be noted that butanone is the main side product from most substrates in Figure 6, again confirming that butanone hydrogenation is the slowest step, possibly because it cannot operate via substrate-directed hydrogenation.

Table 3. Reactions of potential intermediates in the hydrodeoxygenation of erythritol to butenes.

\begin{tabular}{|c|c|c|c|c|c|c|c|}
\hline \multirow{2}{*}{ Entry } & \multirow{2}{*}{ Substrate } & \multicolumn{6}{|c|}{ Yield (\%) } \\
\hline & & Butane & Butenes & Butanone & Propene & Furan & THF \\
\hline 1 & Erythritol $^{\mathrm{a}}$ & o & 43 & 18 & 3 & 6 & o \\
\hline 2 & Butanedione & o & 58 & 11 & 1 & o & $\mathrm{o}$ \\
\hline 3 & 3-Oxobutanala,b & 5 & 37 & 20 & 7 & o & $\mathrm{O}$ \\
\hline 4 & Succinaldehyde ${ }^{\mathrm{a}, \mathrm{b}}$ & 2 & 4 & 0 & 3 & $\mathrm{O}$ & 59 \\
\hline 5 & 3-Hydroxy-2-butanone & 1 & 55 & 17 & $\mathrm{o}$ & $\mathrm{o}$ & $\mathrm{o}$ \\
\hline 6 & 4-Hydroxy-2-butanone & o & 65 & 14 & o & o & o \\
\hline 7 & 1,3-Butanediol & $\mathrm{o}$ & 97 & 1 & 1 & o & $\mathrm{O}$ \\
\hline 8 & 2,3-Butanediol & o & 85 & 10 & o & $\mathrm{o}$ & o \\
\hline 9 & Methylvinylketone & o & 43 & 18 & $\mathrm{O}$ & $\mathrm{o}$ & 0 \\
\hline 10 & Butanone & 3 & 72 & 13 & $\mathrm{o}$ & $\mathrm{o}$ & $\mathrm{o}$ \\
\hline 11 & 1-Buten-3-ol & $\mathrm{o}$ & 83 & 4 & $\mathrm{o}$ & $\mathrm{o}$ & $\mathrm{O}$ \\
\hline 12 & 2-Buten-1-ol & $\mathrm{o}$ & 90 & $\mathrm{o}$ & 1 & $\mathrm{o}$ & 0 \\
\hline 13 & 2-Butanol & 4 & 89 & $\mathrm{o}$ & $\mathrm{o}$ & $\mathrm{o}$ & $\mathrm{o}$ \\
\hline
\end{tabular}

Conditions: $0.5 \mathrm{mmol}$ substrate, o.1 mmol formaldehyde, $1.7 \mathrm{mmol} \mathrm{Bu}_{4} \mathrm{PBr}, 0.025 \mathrm{mmol} \mathrm{HBr}, 0.005 \mathrm{mmol} \mathrm{RuBr}_{3}(1 \mathrm{~mol} \%)$,

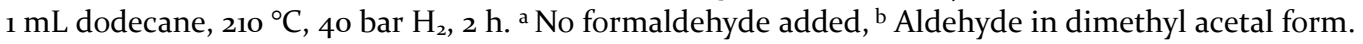

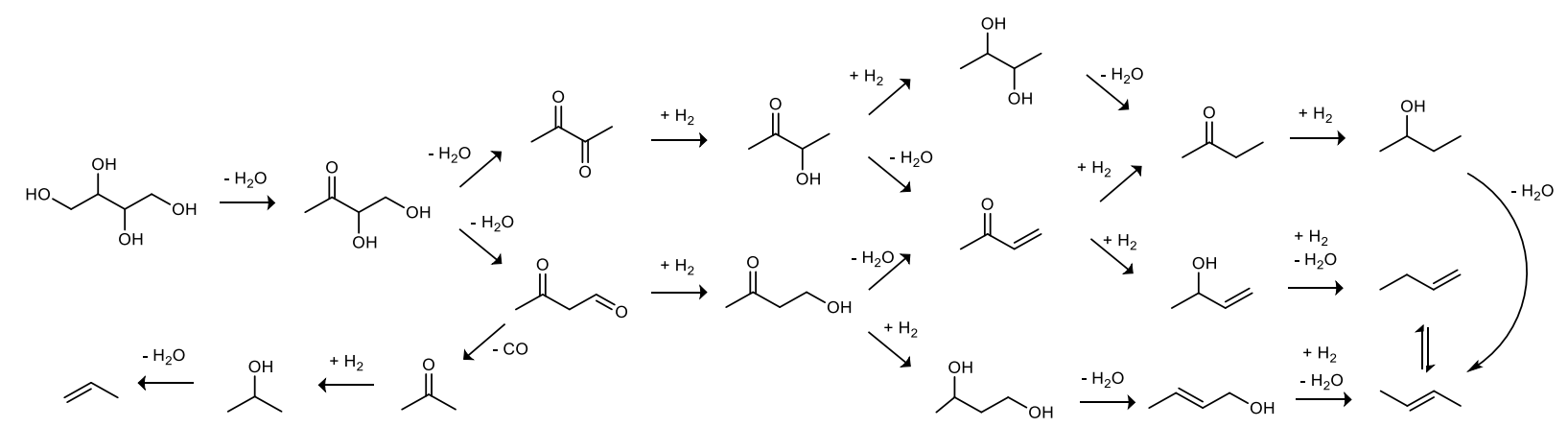

Figure 6. Reaction network for hydrodeoxygenation of erythritol to butenes. For clarity, the bromide substituted and enol intermediates are not shown.

Based on these results, the reaction network in Figure 6 is proposed, showing the most likely pathways. Since dehydration is fast, dicarbonyls are the first products. Butanedione and 3-oxobutanal rather than succinaldehyde are formed, because the bromide substitution occurs preferably on the less sterically hindered outer hydroxy groups. Despite the various reaction types comprised in the network, all reactions eventually converge towards highly selective butene formation. Butenes rather than butadiene are formed for two reasons: first, dehydration of 2,3-butanediol does not lead to butadiene, but rather to butanone,35 and hence to butenes; secondly, allylic 
alcohols/bromides are hydrogenolyzed rather than dehydrated or dehydrobrominated. The formed butenes isomerize, through hydrobromination and dehydrobromination until the thermodynamic equilibrium is reached. A more detailed explanation on the proposed reactions network is available in the Supporting Information.

\section{Expanding the scope: glycerol, xylitol and sorbitol}

As a proof of concept, we investigated hydrodeoxygenation of glycerol, xylitol and sorbitol. The hydrodeoxygenation of glycerol to propene is a particularly interesting reaction, since (crude) glycerol can be cheaply obtained from biomass, and propene is a highly important industrial chemical. Without catalyst pretreatment with $\mathrm{HCHO}$, only a $22 \%$ yield of propene is formed, and significant overreduction to propane occurs $(<50 \%$ selectivity)(Figure 7 a). After pretreatment, the yield strongly increased leading to $57 \%$ propene yield after 1 $\mathrm{h}$ and $66 \%$ after $2 \mathrm{~h}$ at $210^{\circ} \mathrm{C}$.

a

$$
\text { - Propylene }
$$

- Acetone

- 6 compounds

- Conversion

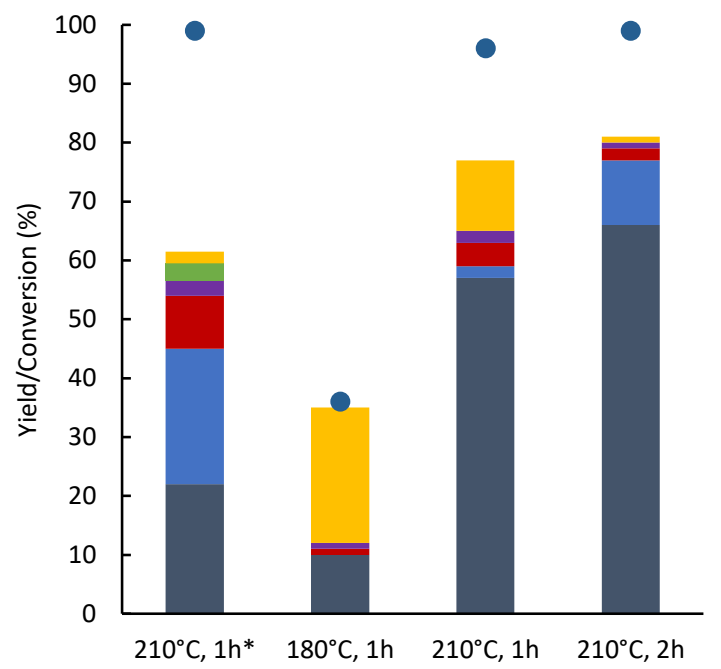

C

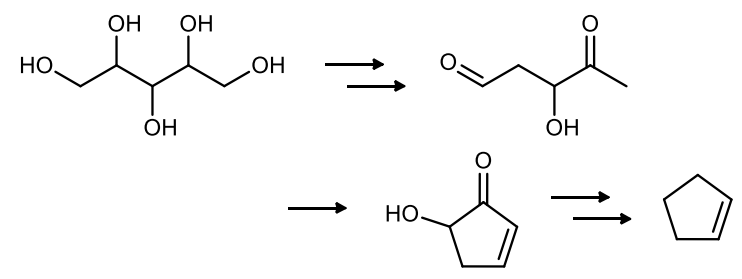

- Propane

- Bromopropanes

Hydroxy compounds

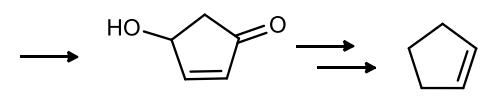

b

- Pentane $\quad$ Linear pentenes $\square$ Cyclopentene

Butane $\quad$ Butenes $\quad$ Pentanoic acid

- Pentenoic acids $\mathbf{a}$ Levulinic acid

- Pentanones

Anhydroxylitols

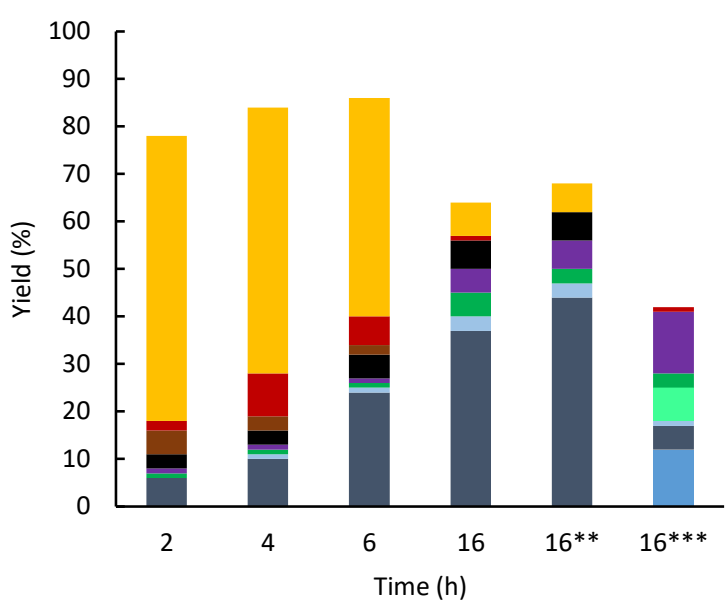

d

- Linear hexenes Cyclic hexenes $\square$ Pentenes

घimethylTHF - Phenol $\quad$ Hexanoic acid

- Hexeneoic acids $\square$ Isosorbide

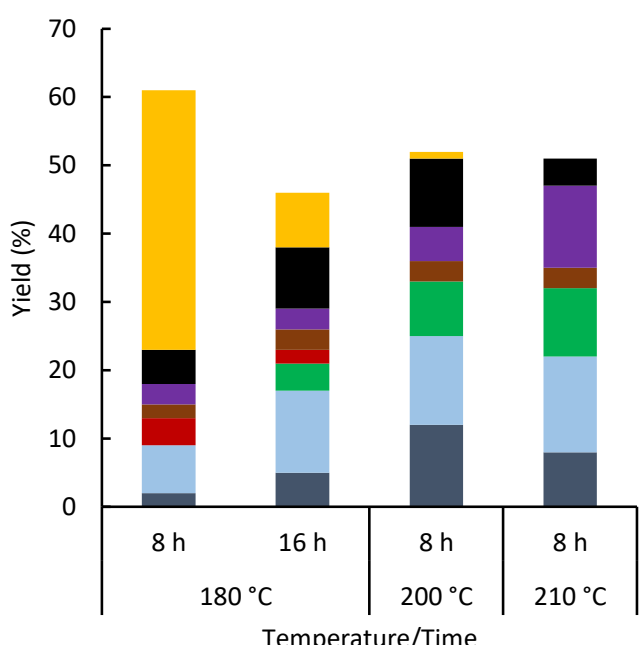


Figure 7. Yield of products in hydrodeoxygenation of different sugar alcohols with $\mathrm{RuBr}_{3} \mathrm{in} \mathrm{Bu}_{4} \mathrm{PBr}$. a) $\mathrm{HDO}$ of glycerol; b) HDO of xylitol $\left(180^{\circ} \mathrm{C}\right)$; c) Plausible mechanism for formation of cyclopentene; d) HDO of sorbitol (3 $\mathrm{mol}_{0} \mathrm{RuBr}_{3}, 0.24$ mmol formaldehyde). Pretreatment conditions: $0.01 \mathrm{mmol} \mathrm{RuBr}_{3}$ (2 mol\%), $0.16 \mathrm{mmol}$ formaldehyde (37 wt\% in water), $1.7 \mathrm{mmol} \mathrm{Bu}_{4} \mathrm{PBr}, 0.025 \mathrm{mmol} \mathrm{HBr}, 210^{\circ} \mathrm{C}, 40$ bar $\mathrm{H}_{2}, 30$ minutes. Reaction conditions: pretreated catalyst in ionic liquid, $0.5 \mathrm{mmol}$ substrate, $1 \mathrm{~mL}$ dodecane, 40 bar $\mathrm{H}_{2}$, indicated temperatures and reaction times. Xylitol and sorbitol conversion is full in all reactions. * Reaction without pretreatment using $1 \mathrm{~mol} \% \mathrm{RuBr}_{3}$; ${ }^{* *} 0.015 \mathrm{mmol} \mathrm{RuBr}_{3}(3$ mol\%) pretreated with $0.24 \mathrm{mmol}$ formaldehyde; ${ }^{* * *}$ reaction without pretreatment at $200^{\circ} \mathrm{C}$. DimethylTHF $=2,5$-dimethyltetrahydrofuran.

Also for xylitol and sorbitol, reactions without pretreatment led to poor results even after long reaction times. In the reaction of xylitol, only $5 \%$ pentenes were formed after $16 \mathrm{~h}$, significant overreduction occurred, and large amounts of side products were formed (Figure $7 \mathrm{~b}$ ). After pretreatment, linear pentenes are the main product from xylitol, but also some cyclopentene is formed. This product could be formed through a series of reactions in which the carbocycle is either formed through intramolecular aldol condensation, or through rearrangement of furfuryl alcohol (Figure 7 c)..$^{8}$ After 16 h, 37\% linear pentenes and 3\% cyclopentene are formed, without overreduction to pentane. Increasing the amount of $\mathrm{RuBr}_{3}$ to $3 \mathrm{~mol} \%$ further improves the yield to $44 \%$ linear pentenes and $3 \%$ cyclopentene. Carboxylic acids and butenes are also produced (Figure S15). While there is still room for improvement, good yields of pentenes are obtained, in a reaction that has not been reported heretofore.

Finally, we performed the challenging reaction of sorbitol using $3 \mathrm{~mol} \% \mathrm{RuBr}_{3}$, and at longer reaction times. A new feature of this reaction is the formation of a recalcitrant cyclic ether, isosorbide (Figure $7 \mathrm{~d}$ ). Increasing the reaction time and/or temperature allows to overcome this issue, leading to higher hexene yields. Both linear and cyclic hexenes, mainly 1-methylcyclopentene, are formed. A total hexene yield of $25 \%$ is reached at $200^{\circ} \mathrm{C}$ after $8 \mathrm{~h}$. Further increasing the temperature does not result in higher yields. The formation of 1-methylcyclopentene probably occurs similarly as described for xylitol to cyclopentene. ${ }^{49}$ Interestingly, this is the first reported formation of cyclic hexenes from sorbitol. Linear hexenes on the other hand have been formed from sorbitol, but only using expensive silanes as the reducing agent. ${ }^{34}$ Again, no overreduction to hexane was observed indicating the high selectivity of the catalytic system. Furthermore, like in the reaction of xylitol, hexanoic acid and hexeneoic acids are formed from sorbitol.

\section{Conclusions}

In conclusion, we have shown that the catalytic dehydration system $\mathrm{HBr} / \mathrm{Bu}_{4} \mathrm{PBr}$ can be combined with a Ru hydrogenation catalyst to perform selective hydrodeoxygenation of erythritol to butenes, avoiding formation of butane. Several homogeneous Ru catalysts lead to good butene yields, but, surprisingly, the best results are obtained with the simple salt $\mathrm{RuBr}_{3}$. CO, which can be added at the start, or formed during reaction, plays a crucial role in formation of the active and selective species. We successfully circumvented the use of this toxic gas, as well as the cumbersome synthesis of the $\left[\mathrm{RuBr}_{2} \mathrm{CO}_{3}\right]_{2}$, by implementing a more elegant pretreatment step using $\mathrm{HCHO}$ as indirect $\mathrm{CO}$-source. The catalytic species was proven to be a homogeneous $\mathrm{Ru}$ (II) carbonyl bromide species by FTIR and EXAFS. In addition, this catalyst also catalyzes hydrodeoxygenation of glycerol to propene in good yields, and the first hydrodeoxygenation of xylitol to pentenes and of sorbitol to hexenes.

\section{AUTHOR INFORMATION}

\section{Corresponding Author}

*E-mail: dirk.devos@kuleuven.be

\section{Author Contributions}

$\S$ These authors contributed equally

Notes

The authors declare no competing financial interest.

\section{ASSOCIATED CONTENT}

\section{Supporting information.}

The Supporting Information is available free of charge on the ACS Publications website. 
Experimental procedures, parameter screening, X-ray absorption spectra, mass spectra of most important products (PDF).

\section{ACKNOWLEDGEMENTS}

M.S. thanks Fonds Wetenschappelijk Onderzoek (FWO) for his doctoral fellowship. K.J. is grateful to KU Leuven for funding through the $\mathrm{C}_{3}$ project 18/o20. EXAFS studies were funded by the President's Grant of Russian Federation (Project MK-2554.2019.2 to A.L.B.). We thank Stef Haesen for experimental work. D.D.V. acknowledges the IWT and FWO for research project funding, the Flemish government for long-term structural funding through Methusalem, and EoS (Biofact) for financial support.

\section{REFERENCES}

(1) Rapaille, A.; Goosens, J.; Heume, M. Sugar Alcohols. In Ullmann's Encyclopedia of Industrial Chemistry; Wiley-VCH Verlag GmbH \& Co: Weinheim, Germany, 2012; pp 1-37.

(2) Gallezot, P. Conversion of Biomass to Selected Chemical Products. Chem. Soc. Rev. 2012, 41 (4), 1538-1558. https://doi.org/10.1039/c1cs15147a.

(3) Corma Canos, A.; Iborra, S.; Velty, A. Chemical Routes for the Transformation of Biomass into Chemicals. Chem. Rev. 2oo7, 107 (6), 2411-2502. https://doi.org/10.1021/cro50989d.

(4) Ayoub, M.; Abdullah, A. Z. Critical Review on the Current Scenario and Significance of Crude Glycerol Resulting from Biodiesel Industry towards More Sustainable Renewable Energy Industry. Renew. Sustain. Energy Rev. 2012, 16 (5), 2671-2686. https://doi.org/10.1016/j.rser.2012.01.054.

(5) Johnson, D. T.; Taconi, K. A. The Glycerin Glut: Options for the Value-Added Conversion of Crude Glycerol Resulting from Biodiesel Production. Environ. Prog. 2007, 26 (4), 338-348. https://doi.org/10.1002/ep.10225.

(6) Moon, H. J.; Jeya, M.; Kim, I. W.; Lee, J. K. Biotechnological Production of Erythritol and Its Applications. Appl. Microbiol. Biotechnol. 2010, 86 (4), 1017-1025. https://doi.org/10.1007/s00253-010-2496-4.

(7) Jeya, M.; Lee, K. M.; Tiwari, M. K.; Kim, J. S.; Gunasekaran, P.; Kim, S. Y.; Kim, I. W.; Lee, J. K. Isolation of a Novel High ErythritolProducing Pseudozyma Tsukubaensis and Scale-up of Erythritol Fermentation to Industrial Level. Appl. Microbiol. Biotechnol. 2009, 83 (2), 225-231. https://doi.org/10.1007/so0253-009-1871-5.

(8) Rakicka, M.; Rukowicz, B.; Rywińska, A.; Lazar, Z.; Rymowicz, W. Technology of Efficient Continuous Erythritol Production from Glycerol. J. Clean. Prod. 2016, 139, 905-913. https://doi.org/10.1016/j.jclepro.2016.08.126.

(9) Ennaert, T.; Feys, S.; Hendrikx, D.; Jacobs, P. A.; Sels, B. F. Reductive Splitting of Hemicellulose with Stable Ruthenium-Loaded USY Zeolites. Green Chem. 2016, 18 (19), 5295-5304. https://doi.org/10.1039/c6gco1439a.

(10) Deneyer, A.; Peeters, E.; Renders, T.; Van den Bosch, S.; Van Oeckel, N.; Ennaert, T.; Szarvas, T.; Korányi, T. I.; Dusselier, M.; Sels, B. F. Direct Upstream Integration of Biogasoline Production into Current Light Straight Run Naphtha Petrorefinery Processes. Nat. Energy 2018, 3 (11), 969-977. https://doi.org/10.1038/s4156o-018-0245-6.

(11) Huber, G. W.; Iborra, S.; Corma, A. Synthesis of Transportation Fuels from Biomass: Chemistry, Catalysts, and Engineering. Chem. Rev. 2006, 106 (9), 4044-4098. https://doi.org/10.1021/cro6836od.

(12) Huber, G. W.; Dumesic, J. A. An Overview of Aqueous-Phase Catalytic Processes for Production of Hydrogen and Alkanes in a Biorefinery. Catal. Today 2006, 111 (1-2), 119-132. https://doi.org/10.1016/j.cattod.2005.10.010.

(13) Chheda, J. N.; Huber, G. W.; Dumesic, J. A. Liquid-Phase Catalytic Processing of Biomass-Derived Oxygenated Hydrocarbons to Fuels and Chemicals. Angew. Chemie - Int. Ed. 2007, 46 (38), 7164-7183. https://doi.org/10.1002/anie.200604274.

(14) Besson, M.; Gallezot, P.; Pinel, C. Conversion of Biomass into Chemicals over Metal Catalysts. Chem. Rev. 2o14, 114 (3), 18271870. https://doi.org/10.1021/cr4002269.

(15) Mota, C. J. A.; Gonçalves, V. L. C.; Mellizo, J. E.; Rocco, A. M.; Fadigas, J. C.; Gambetta, R. Green Propene through the Selective Hydrogenolysis of Glycerol over Supported Iron-Molybdenum Catalyst: The Original History. J. Mol. Catal. A Chem. 2016, 422, 158-164. https://doi.org/10.1016/j.molcata.2015.11.014.

(16) Zacharopoulou, V.; Vasiliadou, E. S.; Lemonidou, A. A. One-Step Propylene Formation from Bio-Glycerol over Molybdena-Based Catalysts. Green Chem. 2015, 17 (2), 903-912. https://doi.org/10.1039/C4GCo1307G.

(17) Zacharopoulou, V.; Vasiliadou, E. S.; Lemonidou, A. A. Exploring the Reaction Pathways of Bioglycerol Hydrodeoxygenation to Propene over Molybdena-Based Catalysts. ChemSusChem 2018, 11 (1), 264-275. https://doi.org/10.1002/cssc.201701605.

(18) Konaka, A.; Tago, T.; Yoshikawa, T.; Shitara, H.; Nakasaka, Y.; Masuda, T. Conversion of Biodiesel-Derived Crude Glycerol into Useful Chemicals over a Zirconia-Iron Oxide Catalyst. Ind. Eng. Chem. Res. 2013, 52 (44), 15509-15515. https://doi.org/10.1021/ie4006645.

(19) Yu, L.; Yuan, J.; Zhang, Q.; Liu, Y. M.; He, H. Y.; Fan, K. N.; Cao, Y. Propylene from Renewable Resources: Catalytic Conversion of Glycerol into Propylene. ChemSusChem 2014, 7 (3), 743-747. https://doi.org/10.1002/cssc.201301041.

(20) Wu, Z.; Yan, H.; Ge, S.; Gao, J.; Dou, T.; Li, Y.; Yip, A. C. K.; Zhang, M. MoO3 Modified Ni2P/Al2O3 as an Efficient Catalyst for Crude Glycerol to Propylene. Catal. Commun. 2017, 92, 80-85. https://doi.org/10.1016/j.catcom.2017.01.oo9.

(21) Dethlefsen, J. R.; Lupp, D.; Teshome, A.; Nielsen, L. B.; Fristrup, P. Molybdenum-Catalyzed Conversion of Diols and BiomassDerived Polyols to Alkenes Using Isopropyl Alcohol as Reductant and Solvent. ACS Catal. 2015, 5 (6), 3638-3647. https://doi.org/10.1021/acscatal.5boo427.

(22) Thibault, M. E.; Dimondo, D. V.; Jennings, M.; Abdelnur, P. V.; Eberlin, M. N.; Schlaf, M. Cyclopentadienyl and Pentamethylcyclopentadienyl Ruthenium Complexes as Catalysts for the Total Deoxygenation of 1,2-Hexanediol and Glycerol. Green Chem. 2011, 13 (2), 357-366. https://doi.org/10.1039/cogcoo255k.

(23) Di Mondo, D.; Ashok, D.; Waldie, F.; Schrier, N.; Morrison, M.; Schlaf, M. Stainless Steel As a Catalyst for the Total 
Deoxygenation of Glycerol and Levulinic Acid in Aqueous Acidic Medium. ACS Catal. 2011, 1 (4), $355-364$. https://doi.org/10.1021/cs20oo53h.

(24) Yang, W.; Grochowski, M. R.; Sen, A. Selective Reduction of Biomass by Hydriodic Acid and Its in Situ Regeneration from Iodine by Metal/Hydrogen. ChemSusChem 2012, 5, 1218-1222. https://doi.org/10.1002/cssc.201100669.

(25) Boucher-Jacobs, C.; Nicholas, K. M. Oxo-Rhenium-Catalyzed Deoxydehydration of Polyols with Hydroaromatic Reductants. Organometallics 2015, 34 (10), 1985-1990. https://doi.org/10.1021/acs.organomet.5boo226.

(26) Shiramizu, M.; Toste, F. D. Deoxygenation of Biomass-Derived Feedstocks: Oxorhenium-Catalyzed Deoxydehydration of Sugars and Sugar Alcohols. Angew. Chemie - Int. Ed. 2012, 51 (32), 8082-8086. https://doi.org/10.1002/anie.201203877.

(27) Raju, S.; Jastrzebski, J. T. B. H.; Lutz, M.; Klein Gebbink, R. J. M. Catalytic Deoxydehydration of Diols to Olefins by Using a Bulky Cyclopentadiene-Based Trioxorhenium Catalyst. ChemSusChem 2013, 6 (9), 1673-168o. https://doi.org/10.1002/cssc.201300364.

(28) Jang, J. H.; Sohn, H.; Camacho-Bunquin, J.; Yang, D.; Park, C. Y.; Delferro, M.; Abu-Omar, M. M. Deoxydehydration of BiomassDerived Polyols with a Reusable Unsupported Rhenium Nanoparticles Catalyst. ACS Sustain. Chem. Eng. 2019, 7 (13), 1143811447. https://doi.org/10.1021/acssuschemeng.9bo1253.

(29) Cook, G. K.; Andrews, M. A. Toward Nonoxidative Routes to Oxygenated Organics: Stereospecific Deoxydehydration of Diols and Polyols to Alkenes and Allylic Alcohols Catalyzed by the Metal Oxo Complex (C 5 Me 5 ) ReO 3. J. Am. Chem. Soc. 1996, 118 (39), 9448-9449. https://doi.org/10.1021/ja9620604.

(30) Stalpaert, M.; De Vos, D. Stabilizing Effect of Bulky $\beta$-Diketones on Homogeneous Mo Catalysts for Deoxydehydration. ACS Sustain. Chem. Eng. 2018, 6 (9), 12197-12204. https://doi.org/10.1021/acssuschemeng.8bo2532.

(31) Ahmad, I.; Chapman, G.; Nicholas, K. M. Sulfite-Driven, Oxorhenium-Catalyzed Deoxydehydration of Glycols. Organometallics 2011, 30 (10), 2810-2818. https://doi.org/10.1021/om2001662.

(32) Tazawa, S.; Ota, N.; Tamura, M.; Nakagawa, Y.; Okumura, K.; Tomishige, K. Deoxydehydration with Molecular Hydrogen over Ceria-Supported Rhenium Catalyst with Gold Promoter. ACS Catal. 2016, $6 \quad$ (10), $6393-6397$. https://doi.org/10.1021/acscatal.6bo1864.

(33) Sun, R.; Zheng, M.; Li, X.; Pang, J.; Wang, A.; Wang, X.; Zhang, T. Production of Renewable 1,3-Pentadiene from Xylitol via Formic Acid-Mediated Deoxydehydration and Palladium-Catalyzed Deoxygenation Reactions. Green Chem. 2017, 19 (3), 638642. https://doi.org/10.1039/C6GCo2868C.

(34) Adduci, L. L.; Mclaughlin, M. P.; Bender, T. A.; Becker, J. J.; Gagné, M. R. Metal-Free Deoxygenation of Carbohydrates. Angew. Commun. 2014, 53, 1646-1649. https://doi.org/10.1002/anie.201306864.

(35) Stalpaert, M.; Cirujano, F. G.; De Vos, D. E. Tetrabutylphosphonium Bromide Catalyzed Dehydration of Diols to Dienes and Its Application in the Biobased Production of Butadiene. ACS Catal. 2017, 7 (9), 5802-5809. https://doi.org/10.1021/acscatal.7bo1765.

(36) Stalpaert, M.; Peeters, N.; De Vos, D. Conversion of Lactide to Acrylic Acid by a Phosphonium Ionic Liquid and Acid Cocatalyst. Catal. Sci. Technol. 2018, 8 (5), 1468-1474. https://doi.org/10.1039/c7cyo2364b.

(37) Kitamura, M.; Ohkuma, T.; Inoue, S.; Sayo, N.; Kumobayashi, S.; Akutagawa, H.; Ohta, T.; Takaya, H.; Noyori, R. Homogeneous Asymmetric Hydrogenation of Functionalized Ketones. J. Am. Chem. Soc. 1988, 110 (2), 629-631. https://doi.org/10.1055/s-198129350.

(38) Ohkuma, T.; Ooka, H.; Ikariya, T.; Noyori, R. Preferential Hydrogenation of Aldehydes and Ketones. J. Am. Chem. Soc. 1995, 117 (41), 10417-10418. https://doi.org/10.1021/jaoo146ao41.

(39) Noyori, R.; Ohkuma, T.; Kitamura, M.; Takaya, H.; Sayo, N.; Kumobayashi, H.; Akutagawa, S. Asymmetric Hydrogenation of $\beta$ Keto Carboxylic Esters. A Practical, Purely Chemical Access to $\beta$-Hydroxy Esters in High Enantiomeric Purity. J. Am. Chem. Soc. 1987, 109 (19), 5856-5858. https://doi.org/10.1021/jaoo253ao51.

(40) Johnson, B. B. F. G.; Johnston, R. D.; Lewis, J. Chemistry of Polynuclear Compounds. Part XV.l Halogenocarbonyl- Ruthenium Compounds. 1969, No. 792, 792-797.

(41) Kitamura, M.; Ohkuma, T.; Inoue, S.; Sayo, N.; Kumobayashi, H.; Akutagawa, S.; Ohta, T.; Takaya, H.; Noyori, R. Homogeneous Asymmetric Hydrogenation of Functionalized Ketones. J. Am. Chem. Soc. 1988, 110 (2), 629-631.

(42) Chen, C.-A.; Chen, Y.-W. Processes for Preparing Formaldehyde, Glycolaldehyde and Ethylene Glycol, 2015.

(43) James, R. Catalytic Decarbonylation. J. Chem. Soc. Chem. Commun. 1980, 939 (2), 939-940.

(44) Sieffert, N.; Réocreux, R.; Lorusso, P.; Cole-Hamilton, D. J.; Bühl, M. On the Importance of Decarbonylation as a Side-Reaction in the Ruthenium-Catalysed Dehydrogenation of Alcohols: A Combined Experimental and Density Functional Study. Chem. - A Eur. J. 2014, 20 (14), 4141-4155. https://doi.org/10.1002/chem.201303722.

(45) Verduyckt, J.; Coeck, R.; De Vos, D. E. Ru-Catalyzed Hydrogenation-Decarbonylation of Amino Acids to Bio-Based Primary Amines. ACS Sustain. Chem. Eng. 2017, 5 (4), 3290-3295. https://doi.org/10.1021/acssuschemeng.6bo314o.

(46) Hoffmann, F. M.; Hoo, Y. S.; Cai, T. H.; White, M. G.; Hrbek, J. Infrared Study of Triruthenium Dodecacarbonyl Interactions with Gold. Surf. Sci. 2012, 606 (23-24), 1906-1913. https://doi.org/10.1016/j.susc.2012.07.036.

(47) Alonso, F.; Beletskaya, I. P.; Yus, M. Metal-Mediated Reductive Hydrodehalogenation of Organic Halides. Chem. Rev. 20o2, 102 (11), 4009-4091. https://doi.org/10.1021/cro102967.

(48) Ulbrich, K.; Kreitmeier, P.; Reiser, O. Microwave- or Microreactor-Assisted Conversion of Furfuryl Alcohols into 4-Hydroxy-2Cyclopentenones. Synlett 2010, 2010 (13), 2037-2040. https://doi.org/10.1055/s-0030-1258534.

(49) Ohyama, J.; Kanao, R.; Ohira, Y.; Satsuma, A. The Effect of Heterogeneous Acid-Base Catalysis on Conversion of 5Hydroxymethylfurfural into a Cyclopentanone Derivative. Green Chem. 2o16, 18 (3), 676-680. https://doi.org/10.1039/c5gco1723h. 
Graphical Abstract (Table of contents)

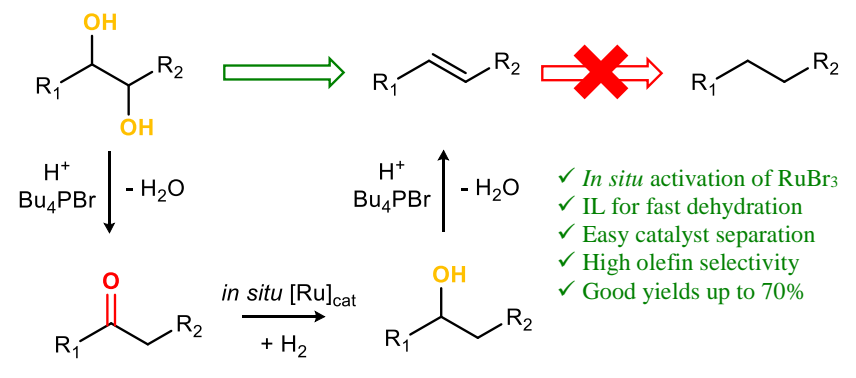

